\title{
The present situation and prospective of China law education
}

\author{
Hong Wang ${ }^{1, a}$ \\ ${ }^{1}$ Liaoning Police College, Dalian, Liaoning Province, China \\ a675087603@qq.com
}

Keywords: China law, legal education, Status quo, Prospective

\begin{abstract}
Through analyzing the current situation of China's law education, found that Chinese education is the education of law targeting is not accurate, the cultivation of practical ability is not in place, the lack of legal professional quality education, put forward to improve China's legal education outlook, such as adjustment of law education pattern, according to different education training ability to set goals; The introduction of case teaching pays attention to the cultivation of practice ability; Deepening legal professional education, etc., for China to develop real meet the actual needs of different levels qualified legal talents..
\end{abstract}

\section{Introduction}

Chinese legal science specialized education faced an embarrassing situation in recent years, on the one hand, the demand for legal professionals are on the increase, on the other hand graduates employment law generally is bad, in the face of such problems we have to reflect on China's current legal education [1]. For decades, China's law education has made big progress in quantity, undoubtedly the most different categories and levels of colleges and universities have set up a legal science specialized, in less than a decade, the national law school has more than seven hundred, seventy students in school more than ten thousand people, so the pace of development for China's law education has the certain positive role [1]. But also brought a lot of new problems, such as unreasonable configuration lead to waste of resources, the lack of practical ability training in education quality is not high. So someone summed up the present our legal education, legal culture edification of weak and narrow professional education, the education law is too utilitarian, less education and students' common multiple personality, such legal education to cultivate people difficult to adapt to the actual needs, also not too easy to do one instance and lines.

\section{The problems in China's law education at present}

Education goal orientation is not accurate. Different categories, different levels of law schools at present in China, basic it is to train legal workers as the goal, and legal workers mostly include judges, prosecutors, lawyers, corporate law workers and researchers. But a qualified legal person should not only grasp the legal professional knowledge, but also have the basic knowledge of other related disciplines, is it possible to handle such cases in different fields; At the same time should also have good logical thinking ability and high professional ethics. These professional knowledge and practical ability has the need to accumulate over a long period, repeated practice, and also need experienced mentors and sufficient teaching resources [2]. Britain's legal education in the university stage is divided into basic knowledge education, vocational skills training and the last phase of the internship, similar to the cultivation of doctors; While the United States to postgraduate education as the starting point of education of law, because they considered legal workers to take more social responsibility, must have rich knowledge and high professional ethics. In contrast, China's law education are mostly get the diploma, for the purpose of all categories, and at all levels all have, also includes the so-called correspondence, community, etc., directly caused the diploma of embarrassment, talented person and the cultivation of the Chinese legal science education shoulder is impossible to achieve the goal of qualified legal talents.

The students lack of ability to control the professional language. Any mature discipline will form professional language, law is no exception. Skilled and accurately using legal language for 
business is a legal person shall have the basic skills [2]. Now, however, a lot of legal science specialized students do not have the basic skills. Law of professional teachers, students in the class comment on some legal issues, often use a specification language expression; Born of graduation thesis is more colloquial English.

Theory teaching from the legal practice. Theory comes from practice; from the practice theory is the theory of the hole. As a mature discipline of law, has a relatively complete theoretical system, to establish the system of the theory of natural system based on legislation and judicial practice for a long time, as the United States justice Holmes said "the life of law lies in experience rather than logic" [3].However, in under the influence of traditional concepts of education, education of law in China has been a focus on imparting the basic theory of jurisprudence, and ignore the cultivation of professional skills, theoretical teaching of law and legal practice. Because most of the students in the whole college never contact with real case, so in the face of a very simple case after graduation I didn't know where to start, let alone use handling skills. Wet behind the shallow at the same time, because of the college students, to adjust by the law of part of the lack of perceptual knowledge, social relations and so on individual department law theory is difficult to understand and grasp. Therefore, the law education should be appropriately increased legal practice.

The cultivation of practical ability is not in place. Current legal education is generally pay attention to instill legal knowledge, learning is mainly the classroom teaching, and the knowledge source of students is not a textbook is the teacher's explanation, and is mostly passively memories on the way, so that students could be systematically mastered the legal knowledge, but with few or no students from beginning to end all have their own ideas and understanding, just remember what the teacher said, textbook how analysis is what, I don't know also not accustomed to from their own Angle to analyze problems, just passively accepting and memory, rather than active critical view of the problems, and legal workers needed most, the most essential is the critical spirit. And jurisprudence of China[3]: most of the teachers from school to school, from theory to theory, their own lack of practical experience, and China's current college teachers evaluation system basically see or scientific research achievements and theoretical articles, as to accord with the characteristics of legal science specialized practice experience is not as the basis, what's more, in the jurisprudence of China: the teacher assumes the main task of the students in major of law, lack of practical experience of the teacher how can cultivate is not lack of practical ability of students? Even if one of the few existing ability training course few similar court mediation, courts, trial practice, or lawyer practice such courses.

Lack of students' comprehensive ability to use law to solve the problem. According to the nature of the legal norms to adjust social relations, legal theory of law can be divided into different departments.Teachers taught law respectively according to different department, so each course taught by just a single department law knowledge;Even need to be quoted cases in the teaching of theory to explain, led by case also is more scholars designed according to some knowledge of small case, such case law knowledge generally do not involve other departments, and even the law does not involve the same department before and after the relevant knowledge [4].The case in reality, however, may not be in accordance with the different department laws and classify to occur, a case is often provisions relating to different department laws.This requires investigators will achieve mastery through a comprehensive, integrated to different departments of law to apply.And our current "fragmented" mode of law teaching is difficult to adapt to the reality.

Students lack of ability to control the professional language. Any mature discipline will form their own professional language, law is no exception.Skilled and accurately using legal language for business is a legal person shall have the basic skills [4].Now, however, a lot of legal science specialized students do not have the basic skills.Law of professional teachers, students in the class comment on some legal issues, often use a specification language expression;Born of graduation thesis is more colloquial English.

Caused the main reason for the lack legal science specialized students' language proficiency has two points: first, the enrollment expansion of colleges and universities makes this imbalance is student-faculty ratios to further expand, causing should small-class teaching specialized courses can 
only large class.Large class must make the student a chance to speak in class greatly reduced, students are lost in the classroom exercises the opportunity of oral expression ability, nature also won't naturally form professional language ability.Secondly, from the teaching practice of law major in colleges and universities, after most of the teachers' teaching is not arrange written work, students during the period of school in addition to writing graduation thesis, basic written expression of exercise opportunity to use professional language.

Most of the graduates of law cannot enter the legal profession. Law graduates in minor authority or law firm is a natural thing, but the reality is that most graduates cannot enter the work unit or organization [4].This is mainly due to China's regulations, judges, prosecutors, lawyers and notaries professional workers, all need through the national organization of the unified judicial examination, in order to obtain the corresponding professional qualification, and most of the graduates of law is not ability through this kind of judicial examination., according to Chinese law "has more than 10 graduates each year, but only a small proportion of students can enter the judicial organ; the current national judicial examination of social average passing rate is about $22 \%$, and the average passing rate of national colleges and universities of political science and law graduates is only 24\%, not much advantage. Visible, law education from" professional "far away".

Literacy education lack of legal profession. China's legal development in modern history the biggest characteristic is the exogenous model development, is not the development of the local internal spontaneous type, so to some extent is lacking legal culture and the spirit of the law.Although the development of legal culture for decades have great progress, but because of lack of still has problems that resulted in, such as the current law education too much emphasis on legal knowledge and the training of the law, but completely ignore the law professional quality, not to mention to the cultivation of students thinking ability and critical spirit, leads to many of the legal science specialized student graduated from only know the law, legal culture, more do not know the law behind the origin and value in it [3]. The result is not very ideal, although the law as the change of external environment, law will continue to improve, but the same is the law of things, such as the spirit of the law and legal culture, and legal value, etc.Law is not lonely discipline at the same time, must also can combine with other disciplines, to accomplish the mission of legal workers, play the role of law.China is now the lack of professionalism in the education of law, lead to the students' study purpose is too utilitarian, only as a tool and means, lack of the pursuit of legal value and legal person shall have the social sense of responsibility.This kind of education environment to cultivate tools by laws of speculators, adventurer, rather than the law supreme justice angel.

\section{Prospective of legal education reform in China}

Reform in the teaching material of writing mode. Law teaching professional shall follow the principle of paying equal attention to both theory and practice.The author thinks that, representative, inspirational case should be a large number of materials into law, in order to deepen students' understanding of the theory and enhance students' ability to analyze and solve problems, make the teaching more targeted and operability and effectiveness [5].Especially strong theoretical teaching materials, such as general jurisprudence, civil law and legal thought, more should be combined with a large number of cases to explain to the theory and analysis, makes the student to the abstract theory have a perceptual knowledge.At present, the individual legal textbooks have been trying to put a large number of cases into teaching materials, but mostly in theory content of each chapter, after the case listed in the assignments section for informative, generally do not do the analysis.This although compared with the traditional jurisprudence teaching mode has improved, but the case is not in the content of the theory of thrust, and the lack of proper analysis, so the effect is not ideal.

Attaches great importance to the practice teaching link. Only fully attaches great importance to the practice teaching, can produce can meet the social need of practical talents.Therefore, the author suggested that should pay attention to professional practice teaching of law.First of all, we should establish perfect the practice teaching system.Law practice ability and practice ability of students, to a large extent depends on the law practice teaching course system design and planning of [5].Professional practice teaching system of law can be made by classroom practice teaching and 
social practice two parts.Practice teaching in classroom teaching mainly include the case analysis, problem discussion, moot court trial, etc.;Social practice, including legal clinics, law practice, social practice and so on.Next, want to incorporate the necessary practical courses required course.For example, "lawyer practice" and "legal clinic" "writing" legal document "legal practice curriculum" should be opened as a required course.Third, we should set up scientific mechanism of supervision and review of the practice teaching. Only by establishing scientific practice ability appraisal mechanism, can truly will practice teaching in effect, avoid to become a mere formality;Also can improve the quality of legal professional personnel training aspects emphatically.

Adjustment of law education pattern, according to different education training ability to set goals. Optimize the structure of China's law education should first according to the actual situation of colleges and universities themselves, cultivating ability, teachers, teaching resources, establishing different, possible education goals [5].Law education must abide by the law of talent training, such as affordable legal education for the franco-prussian priority, mainly in order to strengthen people's legal consciousness, strengthening people's idea of rule of law, in order to give full play to the social service function method, create a good social environment for the rule of law;Practice model of legal education should pay attention to cultivate the students' ability to apply natural.

The introduction of case teaching pays attention to the cultivation of practice ability. Law belongs to applied science, not only stay on the books, it will ultimately be combined with the actual.Law application will have the ability to analysis law, summarized the ability of legal fact and persuasive rigorous reasoning ability, etc.By that standard, the place where we lack too much, basically have the following several aspects [6]:

1) The real implementation of case teaching.Case teaching is always first to set conditions and problems, which can arouse students' interests, stimulate students' active thinking, to make the students to look for ways to solve the problem in the process of understanding and mastering the law, the students' knowledge originates from practice.The teacher plays the role of the guide, work together with students.

2) Guide students to establish multiple thinking direction, can use different character's point of view the same case, find the best solution for the interests of the different roles.Normative legal thinking is very strong, cannot leave a normative legal term, law is also a strong logical thinking, adhere to the syllogism, need to be calm and careful, so the law need thinking mode and thinking Angle is acquired repeated training, and training of this kind does not have a fixed mode, stay flexible.

3) The instructor to diversification.Cannot be confined to a high degree of legal science research personnel, but also can be engaged in the practice of legal workers, such as lawyers, judges, enterprise legal persons, each one legal workers brought students from different areas are different experience and thinking;Can also take measures to enhance the school teachers' practical ability, the world famous law school teacher would take a certain amount of time engaged in legal practice.

4) To reposition the student internship programs, to make students really gained in practice.Internship program is legal effective means to cultivate applied talents.Schools to timely communication and coordination with the internship institutions, scientific arrangement practice course of time, as far as possible to reduce or avoid conflict with all kinds of test time, schools can also set up their own practice base, equipped with their own practice guidance teacher, let practice courses truly become a compulsory course for students majoring in law.

Deepen the law professional quality education.The legal profession as doctors, teachers, are the professional of man-made objects, has a strong professional and unique professional characteristics, in addition to a certain degree of professional knowledge, also have a series of professional quality.The cultivation of the legal literacy learning generally includes the law related disciplines, such as basic knowledge of economics, otherwise can not be well dealing with civil and commercial law, economic law cases of disputes;Such as administrative duty of functional departments and business scope of the study, otherwise we are not good on administrative affairs [6].Also include the legal culture and related study of natural science.Legal culture is a legal system, legal infrastructure, legal behavior behind the common ideas and values, is the ideological root of real implementation of 
the law, to understand the legal culture can understand the things behind the law.Also includes the cultivation of the concept of fairness and justice, faith and the rule of law and legal advocate, it is the core essential factor of success for legal talents training work, belief in the rule of law and upholding the law is the law is supreme, power standard, this just is the inherent requirement of the rule of law concept.

\section{Summary}

Legal education is the precondition of China to achieve ideal country under the rule of law, since don't have to say more, the importance of law education reform development is the inevitable requirement of the rule of law construction in China. For decades, the education of law in China has been looking for our own way, and there is no doubt that in the process, we have made significant progress, but at the same time we must see many problems existing in the current legal education. Only realize the problems of reality, can we effectively, targeted for reflection and to try new things. Through to accurate positioning of the target of China's law education, through the reasonable use of scientific methods, such as case type teaching, and the deepening of legal workers professional quality cultivation and education of law in China will have a bright future.

\section{References}

[1] H.M. Luo Hong, Education policies and regulations, Shanghai: the popular science press, 1992, pp. 12-16.

[2] K.H. Zhao, Education regulations tutorial, Nanjing: Jiangsu education press, 2011, vol.3, pp.35-38.

[3] H.Sh. Zhang, W.Y. Zhou, Introduction to education law, Qingdao: Qingdao ocean university press, 2012, vol.6, 56-61.

[4] H.S. Wen, Contemporary legal education of jurisprudence perspective, The jurists, 2002, vol,2,32-36.

[5] B.Sh. Wang, The theory of legal talents cultivation, The legal and social development, 2011, vol.2, pp.10-13.

[6] Ch.M. Cheng, After the accession to the WTO the trend of the development of the Chinese legal science education , The legal daily on October 17, 2002 